\title{
Valerio Cordiner, Mani unte. La giustizia ai tempi di
} Gouberville

\section{Filippo Fassina}

\section{(2) OpenEdition}

\section{Journals}

\section{Edizione digitale}

URL: http://journals.openedition.org/studifrancesi/2112

DOI: 10.4000/studifrancesi.2112

ISSN: 2421-5856

\section{Editore}

Rosenberg \& Sellier

\section{Edizione cartacea}

Data di pubblicazione: 1 aprile 2014

Paginazione: 131

ISSN: 0039-2944

\section{Notizia bibliografica digitale}

Filippo Fassina, «Valerio Cordiner, Mani unte. La giustizia ai tempi di Gouberville», Studi Francesi [Online], 172 (LVIII | I) | 2014, online dal 01 avril 2014, consultato il 18 septembre 2020. URL : http:// journals.openedition.org/studifrancesi/2112 ; DOI : https://doi.org/10.4000/studifrancesi.2112

Questo documento è stato generato automaticamente il 18 settembre 2020.

\section{(c) $(7)$}

Studi Francesi è distribuita con Licenza Creative Commons Attribuzione - Non commerciale - Non opere derivate 4.0 Internazionale. 


\title{
Valerio Cordiner, Mani unte. La giustizia ai tempi di Gouberville
}

\author{
Filippo Fassina
}

\section{NOTIZIA}

VALERIO CORDINER, Mani unte. La giustizia ai tempi di Gouberville, Manziana, Vecchiarelli Editore, 2012, («Negotia litteraria», 15), pp. 125.

1 Il rapporto fra giustizia e organizzazione dello Stato è questione di grande interesse, ma forse poco nota all'interno della storia letteraria francese del Cinquecento. L'A. intende dare un contributo chiarificatore e, in primo luogo, confutare l'opinione comune secondo la quale il Rinascimento segnerebbe un'evoluzione nel sistema statale francese in senso moderno. Per dimostrare, al contrario, che la sovrastruttura economica e politica è ancora ampiamente vincolata a un sistema feudale di origini medievali, l'A. offre un esempio concreto, presentando questa monografia su Gilles Picot, sieur de Gouberville (1521-1578), proprietario terriero e juge forestier. Oltre a fornire una ricca biografia dell'amministratore della giustizia, senza tralasciare numerose informazioni sui suoi più stretti collaboratori, il lavoro qui presentato descrive un vivacissimo spaccato della società francese cinquecentesca, nella quale «l'amministrazione della giustizia, come d'altronde tutti gli altri poteri dello Stato, sono allora e resteranno a lungo saldamente in mano al secondo stato, funzionale sovrastruttura che interagisce dialetticamente con un'infrastruttura socio-economica ancora in larga parte fondata sulla rendita. Feudale l'una pertanto, come e perché feudale è l'altra» (p. 117). L'aspetto che in questo testo viene costantemente ribadito è che la faziosità e la corruzione sono parte integrante, se non cardine, di un sistema politico e giuridico ancora ampiamente lontano dal concetto moderno di Stato. 